\title{
Pengujian Pelumas Bekas SAE 15W-40 API CI-4
}

\author{
Abeth N Sonjaya *, Fauzhia Rahmasari \\ Program Studi Teknik Mesin Fakultas Teknologi Industri Universitas Jayabaya \\ *) Corresponding author: abethw21@gmail.com \\ (Received 04-Oct-19・Revised 26-Oct-19・Accepted 29-Nov-2019)
}

\begin{abstract}
Lubricants act as anti-friction media and help in reducing the wear of the components in contact during the motion of the machine parts. Around the globe, petroleum-based reserves are going to deplete, which could result in a price hike and create concern about environmental pollution. This study examines reprocessing used SAE 15W-40 CI-4 lubricants into used lubricating oil that can be used for low-speed lubricants. SAE 15W-40 CI-4 used lubricant oil that has been used in car engines has changed physical and chemical properties, which contain water from burning fuel, metal wear particles, soot, and oxidizing lubricants such as sludge and corrosive acids. The research method used to separate impurities contained in SAE 15w-40 CI-4 used lubricating oil is by adsorption process and testing of several types of engine lubricants namely DEO API CI-4 SAE 15W-40, PCMO API SN SAE 10W-40, MCO API SL SAE 10W-30, HO ISO VG 32, TO API TO-4 SAE 10W with viscosity and additives, using the ASTM test method, for the index viscosity test (ASTM D2270), Pour Point (ASTM D97) and Flash Point (ASTM D92). The results showed that the higher the class of raw materials used for the manufacture of lubricants, the better the quality of the lubricant that includes the index viscosity, pour point, and flashpoint.
\end{abstract}

\begin{abstract}
Abstrak
Pelumas bertindak sebagai media anti-gesekan dan membantu mengurangi keausan komponen selama kontak dengan gerakan bagian-bagian mesin. Di seluruh dunia, cadangan berbasis minyak bumi akan menipis sehingga dapat menyebabkan kenaikan harga dan menciptakan kekhawatiran pencemaran lingkungan. Studi ini mengkaji mengolah kembali minyak pelumas bekas SAE 15W-40 API CI-4 menjadi minyak pelumas bekas yang dapat dimanfaatkan untuk pelumas putaran rendah. Minyak pelumas bekas SAE 15W-40 API CI-4 yang telah digunakan pada mesin mobil, mengalami perubahan sifat fisik maupun kimia, yakni mengandung air hasil pembakaran bahan bakar, partikel keausan logam, jelaga, dan oksidasi pelumas seperti lumpur dan asam yang bersifat korosif. Metode penelitian yang digunakan untuk memisahkan zat pengotor yang terkandung pada minyak pelumas bekas SAE 15W-40 API CI-4 adalah dengan proses adsorbsi (penjerapan) dan pengujian beberapa jenis pelumas mesin yaitu DEO API CI-4 SAE 15W-40, PCMO API SN SAE 10W-40, MCO API SL SAE 10W30, HO ISO VG 32, TO API TO-4 SAE 10W dengan kekentalan dan penambahan aditif, menggunakan metode uji ASTM, untuk uji viskositas indeks (ASTM D2270), Titik Tuang (ASTM D97) dan Titik Nyala (ASTM D92). Hasil penelitian menunjukkan bahwa semakin tinggi golongan bahan baku yang digunakan untuk pembuatan pelumas, maka semakin bagus kualitas pelumas yaitu meliputi viskositas indeks, titik tuang dan titik nyala.
\end{abstract}

Keywords: Adsorption, Engine Lubricant SAE 15W-40 API CI -4, Lubricant ASTM 


\section{PENDAHULUAN}

Banyak peneliti di seluruh dunia telah berusaha untuk meningkatkan keramahan lingkungan, ketergantungan dan efisiensi energi di sektor otomotif [1]. Kemajuan teknologi memberikan solusi seperti penggunaan lightweight materials, gas buang setelah perawatan, bahan bakar yang kurang berbahaya dan pembakaran terkendali adalah beberapa cara yang telah disarankan sebagai cara untuk mengurangi masalah lingkungan yang diciptakan oleh kendaraan dan mesin [2]. Pelumasan adalah proses atau teknik yang digunakan untuk mengurangi keausan dari satu atau ke dua permukaan dalam jarak dekat, dan bergerak relatif terhadap masing-masing lainnya, dengan menempatkan zat yang disebut pelumas di antara permukaan untuk membawa atau untuk membantu membawa beban (tekanan yang dihasilkan) antara permukaan yang berlawanan. Tujuan utama pelumasan adalah (i) untuk mengurangi gesekan dan mencegah hilangnya panas yang terjadi akibat kontak permukaan yang bergerak, (ii) untuk melindunginya dari korosi dan mengurangi oksidasi; (iii) untuk bertindak sebagai isolator dalam aplikasi transformator; dan (iv) untuk bertindak sebagai agen pelapis terhadap kotoran, debu, dan air. Sementara aus dan panas tidak bisa sepenuhnya dihilangkan, aus dan panas dapat dikurangi pada level tertentu menggunakan pelumas. Karena panas dan aus dikaitkan dengan gesekan, kedua efek dapat diminimalkan dengan mengurangi koefisien gesekan antara permukaan yang bersentuhan.

Pelumas tersedia dalam bentuk cairan, padat dan gas, pelumas cair dan padat atau setengah padat digunakan secara luas dalam kehidupan sehari-hari [3]. Persyaratan pelumasan yang efektif pada kondisi operasi yang diinginkan untuk pengoperasian kendaraan otomotif yang aman dan andal adalah wajib untuk mengurangi gesekan dan keausan, khususnya pada engine dan drive train. Telah lama minyak mineral digunakan sebagai pelumas untuk otomotif, namun sebagai produk penyulingan minyak mentah, penggunaannya dibatasi oleh ketersediaan cadangan minyak mentah. Selain itu, pembuangan minyak mineral menyebabkan degradasi di darat, air dan ekosistem [4]. Selanjutnya emisi dari logam seperti kalsium, magnesium, partikel besi dan seng karena pembakaran minyak mineral sebagai pelumas menyebabkan kekhawatiran tentang degradasi lingkungan [5]. Apalagi saat ini dan prospek masa depan minyak mineral sebagai pelumas mesin mobil telah diprediksi meningkat untuk masa yang akan datang. Oleh karena itu, perlu dikaji untuk mengidentifikasi alternatif penggunaan kembali pelumas bekas yang telah digunakan untuk mesin pembakaran dalam (internal Engine).

Menipisnya cadangan minyak mentah dan peningkatan kenaikan harga minyak telah mengarah pada pencarian global yang inovatif untuk pengembangan dan menggunakan pelumas yang efektif untuk melindungi kerusakan lingkungan yang disebabkan oleh minyak pelumas dan tumpahannya yang tidak terkontrol [6]. Salah satu contoh kasus penggunaan minyak pelumas SAE 15W-40 API CI-4 yang banyak digunakan dibengkel di PT Serasi Auto Raya tahun 2018. Pemakaian pelumas SAE 15W-40 API CI-4 adalah pelumas multigrade sehingga dapat dipakai untuk kendaraan mesin bensin maupun mesin diesel dengan pemakaian jarak tempuh maksimal rata-rata adalah 10.000 kilometer. Tabel 1. memperlihatkan pemakaian minyak pelumas SAE $15 \mathrm{~W}-40$ API CI-4 yang paling sering digunakan tercatat sebanyak 190.597 liter di tahun 2018. 
Tabel 1. Pemakaian Minyak Pelumas

\begin{tabular}{ccc}
\hline Tipe & Quantity (liter) & Quantity Scrap (liter) \\
\hline 0w20 & 581 & 464 \\
$10 \mathrm{w} 30$ & 23.864 & 19.091 \\
$10 \mathrm{w} 40$ & 48.338 & 38.670 \\
$15 \mathrm{w} 40$ & 190.597 & 152.478 \\
$5 \mathrm{w} 30$ & 1.570 & 1.256 \\
$80 \mathrm{w} 90$ & 5.872 & 4.698 \\
$85 \mathrm{w} 140$ & 10.526 & 8.421 \\
ATF & 333 & 266 \\
CVT & 46 & 37 \\
Others & 47.507 & 38.005 \\
SAE90 & 35.280 & 28.224 \\
Total & 364.512 & 291.609 \\
\hline
\end{tabular}

Studi ini mengkaji mengolah kembali minyak pelumas bekas SAE $15 \mathrm{~W}-40$ API CI-4 menjadi minyak pelumas bekas yang dapat dimanfaatkan untuk pelumas putaran rendah. Minyak pelumas bekas SAE 15W-40 API CI-4 yang telah digunakan pada mesin mobil, mengalami perubahan sifat fisik maupun kimia, yakni mengandung air hasil pembakaran bahan bakar, partikel keausan logam, jelaga, dan oksidasi pelumas seperti lumpur dan asam yang bersifat korosif. Untuk itu metode penelitian yang digunakan untuk memisahkan zat pengotor yang terkandung pada minyak pelumas bekas SAE 15W-40 API CI-4 adalah dengan proses adsorpsi (penjerapan). Adsorpsi (penjerap) merupakan suatu proses perpindahan massa adsorbat dari fase gerak (fluida pembawa adsorbat) ke permukaan adsorben. Faktorfaktor yang mempengaruhi proses adsorpsi yaitu sifat kimia dan fisik adsorben seperti ukuran pori, komposisi kimia dan luas permukaan. Sifat kimia dan fisik adsorbat yaitu kepolaran, ukuran dan komposisi kimia molekul, $\mathrm{pH}$, suhu, dan konsentrasi adsorbat dalam fasa cair. Sebagai zat penjerap, adsorben harus memiliki luas permukaan per satuan massa yang besar, daya ikat yang kuat terhadap zat yang akan dipisahkan secara fisik dan kimia dan tidak boleh terbawa pada fluida tersebut. Beberapa penelitian yang sudah dilakukan [7-11], menetapkan penggunaan suhu pemanasan, lama waktu penjerap, laju alir dan waktu kontak sebagai variabel bebas, sedangkan pemilihan jenis penjerap yang digunakan belum dilakukan kajian lebih lanjut dalam rangka untuk memperoleh hasil terbaik. Di satu sisi, jenis penjerab merupakan salah satu faktor penentu keberhasilan proses adsorbsi. Atas dasar pada penelitian terdahulu, maka akan di teliti jenis penjerap yaitu karbon aktif, silika gel, dan bentonit untuk menjerap (mengadsorb) minyak pelumas bekas SAE 15W-40 API CI-4 agar dihasilkan karaktersitik pelumas bekas yang baik, sedangkan untuk variabel yang digunakan adalah suhu pemanasan, waktu operasi dan pengadukan dibuat tetap sesuai dengan hasil terbaik yang diperoleh dari penelitian terdahulu. Tujuan penelitian ini adalah mendapatkan karakterisasi sifat fisik minyak pelumas bekas SAE 15W-40 API CI-4 terhadap senyawa kandungan logam dan mendapatkan jenis penjerap terbaik terhadap sifat fisik pelumas bekas, dan mengkaji perbedaaan jenis minyak dasar (base oil) terhadap mutu dari suatu produk pelumas dengan melakukan uji karakteristik yang dilakukan di Laboratorium Intertek Jakarta dengan pengujian fisika dan kimia menggunakan metode uji ASTM yaitu viskositas kinematic pada suhu $40^{\circ} \mathrm{C}$ dan $100^{\circ} \mathrm{C}$ (ASTM D445), viskositas indeks (ASTM D2270), total base number (ASTM D2896), titik tuang (ASTM D97) dan titik nyala (ASTM D92). Luaran yang ingin dicapai dari penelitian ini adalah dapat mengetahui mutu pelumas mesin yang dibuat dari berbagai jenis bahan dasar dan pelumas bekas. 


\section{METODE PENELITIAN}

\section{Bahan dan Alat Penelitian}

Bahan baku utama yang digunakan pada penelitian ini adalah minyak pelumas bekas SAE 15W-40 API CI-4 yang diperoleh dari bengkel PT Serasi Auto Raya (PT Astra Grup) dengan spesifikasi wujud cair, warna coklat kehitaman. Bahan - bahan pembantu yang digunakan : Karbon aktif, silika gel, dan bentonit yang memiliki spesifikasi sebagai berikut: karbon aktif dalam fase padat, berbentuk serpihan dengan ukuran $0,3-0,5 \mathrm{~cm}$, berwarna hitam, dan tidak berbau; silika gel dalam fase padat, berbentuk butiran dengan ukuran $0,3 \mathrm{~cm}$, berwarna putih, dan tidak berbau; bentonit dalam fase padat, berbentuk serbuk dengan ukuran 100 mesh, berwarna coklat muda, dan tidak berbau.

Peralatan yang digunakan dalam penelitian adalah satu unit alat penjerapan yang terdiri dari: (1) glass ware bahan kaca (2) Waterbath dengan diameter bahan konstruksi aluminium (3) Agitator (4) Kompor Listrik (5) Thermostat.

\section{Waktu dan Tempat}

Penelitian dilaksanakan di laboratorium FTI Universitas Jayabaya, dan Pengujian sampel dilakukan di PT Intertek dan PT Prolab Jakarta. Penelitian dilaksanakan bulan Januari 2019 sampai Juli 2019.

\section{Diagram Alir Penelitian}

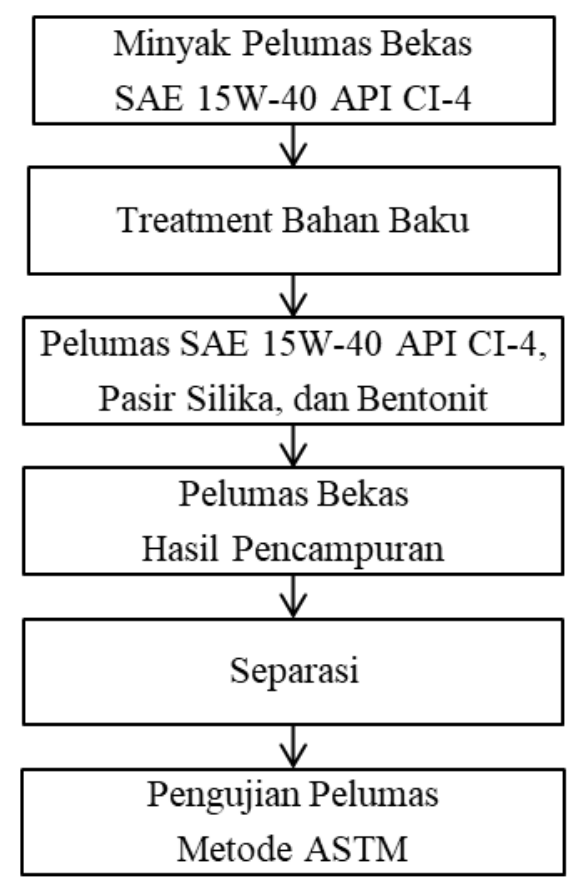

Gambar 1. Diagram Alir Penelitian 


\section{Prosedur Penelitian}

Penelitian dilakukan dalam tiga tahapan. Tahap pertama yaitu karaktersitik pelumas bekas SAE 15W-40 CI-4, tahap kedua adalah proses penjerapan untuk menghilangkan kontaminan berupa bahan padat, logam, dan air. Percobaan dilakukan pada jenis penjerap karbon aktif, silika gel dan bentonit. Pengujian minyak pelumas meliputi viskositas kinematik, viskositas indeks, dan specific gravity. Pengujian karakteristik pelumas dengan menggunakan metode pengujian ASTM pelumas yaitu viskositas kinematik pada suhu $40{ }^{\circ} \mathrm{C}$ dan $100{ }^{\circ} \mathrm{C}$ (ASTM D445), viskositas indeks (ASTM D2270), total base number (ASTM D2896), titik tuang (ASTM D 97) dan titik nyala (ASTM D 92).

\section{Karakterisasi Pelumas SAE 15W-40 API CI-4}

\section{Analisa Viskositas Kinematik}

Sampel disaring terlebih dahulu sebelum dimasukkan ke dalam viscometer, kemudian ukuran viskometer dipilih yang sesuai dengan kekentalan sampel yang akan diukur. $15 \mathrm{~mL}$ sampel dimasukkan ke dalam ubbelohde viscometer glass sampai pada tanda batas pengisian. Viscometer glass diletakkan ke dalam dudukannya dan dimasukkan ke dalam termostat yang telah diatur suhunya $40^{\circ} \mathrm{C}$. Tekan tombol start untuk mulai pengukuran. Stopwatch dihidupkan pada saat sampel turun dimulai dari batas atas sampai batas bawah. Catat waktu yang tertera pada display atau stopwatch.

\section{Indeks Viskositas (ASTM D2270)}

Indeks viskositas (VI) merupakan bilangan empiris yang menunjukkan sifat perubahan viskositas minyak pelumas terhadap perubahan suhu. Minyak pelumas dengan indeks viskositas (VI) lebih rendah adalah minyak pelumas dengan rentang perubahan viskositas yang lebih besar untuk perbedaan suhu yang sama. Minyak pelumas dengan indeks viskositas tinggi, pelumasannya akan berlangsung lebih baik dengan rentang perbedaan suhu yang lebih lebar. Oleh karena itu, indeks viskositas minyak pelumas dibatasi oleh nilai minimunnya.

\section{Densitas (ASTM D4052)}

Densitas adalah perbandingan berat massa $(\mathrm{kg})$ per berat volume $\left(\mathrm{m}^{3}\right)$. Densitas suatu pelumas merupakan fungsi dari suhu. Kegunaan dari parameter densitas adalah: sebagai indikator kelarutan aditif pada pelumas dan pendukung adanya fraksi-fraksi kontaminan pada pelumas. Cara kerja: sampel diambil dengan menggunakan syringe dengan ukuran volum 2 $\mathrm{mL}$, lalu diinjeksikan dalam alat digital density meter kemudian tekan tombol start pada alat ditunggu sampai kondisi pengujain valid kemudain cacat hasil yang tertera pada layar alat.

\section{Titik Tuang}

Titik tuang atau pour point adalah indikator mudah atau tidaknya minyak pelumas tersebut membeku pada suhu tertentu. Apabila minyak pelumas cepat membeku, maka pelumasan akan mengalami kegagalan. Oleh karena itu titik tuang perlu dibatasi nilai maksimumnya. Pengujian titik tuang dilakukan dengan metode ASTM D97. 


\section{Titik Nyala}

Titik nyala minyak pelumas adalah kondisi penguapan jenuh di atas permukaan minyak pelumas di bawah suhu minimum, dimana pada kondisi ini minyak pelumas akan mudah menyala (terbakar sesaat). Selain itu juga dapat mengidentifikasi sifat penguapan jenis minyak pelumas dasar yang digunakan pada formulasi. Oleh karena itu karaktersitik titik nyala perlu dibatasi nilai minimumnya. Titik nyala merupakan sifat pelumas yang digunakan untuk prosedur penyimpanan agar aman dari bahaya kebakaran. Semakin tinggi titik nyala suatu pelumas berarti semakin aman dalam penggunaan dan penyimpanan. Pengujian titik nyala dilakukan dengan metode ASTM D93.

\section{HASIL DAN PEMBAHASAN}

\section{Karakterisasi Minyak Pelumas, Base Oil, dan Minyak Pelumas Bekas}

Karakterisasi minyak pelumas, base oil, dan minyak pelumas bekas meliputi viskositas kinematik, indeks viskositas (IV), dan spesifik gravity (Sg). Karakterisasi minyak pelumas, base oil, dan minyak pelumas bekas dapat dilihat pada Tabel 2 dan kandungan senyawa logam minyak pelumas dapat dilihat pada Tabel 3.

Tabel 2. Karakterisasi Pelumas Bekas SAE 15W-40 CI-4, HVI 95, dan minyak pelumas

\begin{tabular}{cccc}
\hline Pembanding & Viskositas Kinematik (cp) & IV & Sg \\
\hline Pelumas bekas SAE & 59,880 & 0,015 & 0,870 \\
15W-40 API CI-4 & 61,945 & 0,015 & 0,953 \\
Base oil (HVI 95) & 55,857 & 0,016 & 0,866 \\
Oli baru & &
\end{tabular}


Tabel 3. Kandungan Logam Minyak Pelumas Bekas SAE 15W-40 API CI-4

\begin{tabular}{|c|c|c|c|}
\hline Senyawa & $\begin{array}{c}\text { Nilai Kandungan } \\
\text { Logam }\end{array}$ & Senyawa & $\begin{array}{c}\text { Nilai Kandungan } \\
\text { Logam }\end{array}$ \\
\hline $\operatorname{Ag}(328.068)$ & 0,1 & $\mathrm{Na} 588.995$ & 86 \\
\hline $\mathrm{Al}(257.509)$ & 28 & Nb 295.088 & 1 \\
\hline As $(188.980)$ & 2 & Ni 231.604 & 1 \\
\hline $\mathrm{Ba}(455.403)$ & 1 & P 213.618 & 927 \\
\hline $\mathrm{Bi}(223.061)$ & 1 & $\mathrm{~Pb} 220.353$ & 4 \\
\hline $\mathrm{Ca}(318.127)$ & 1943 & S 181.972 & 1136440 \\
\hline $\mathrm{Cd}(214.439)$ & 0 & Sb 206.834 & 0 \\
\hline Co $(235.341)$ & -1 & Sc 361.383 & 0 \\
\hline $\operatorname{Cr}(267.716)$ & 2 & Se 196.026 & 3 \\
\hline $\mathrm{Cu}(219.959)$ & 2 & Sn 189.927 & 0 \\
\hline $\mathrm{Fe}(259.940)$ & 37 & Sr 460.733 & 2 \\
\hline $\mathrm{Ga}(294.363)$ & 0 & Та 268.517 & -3 \\
\hline K (766.491) & 31 & Te 214.282 & 0 \\
\hline $\mathrm{La}(398.852)$ & 0 & Ti 336.122 & 11 \\
\hline Li (670.783) & 0 & V 311.837 & 0 \\
\hline $\operatorname{Mg}(280.270)$ & 20 & W 207.912 & 7 \\
\hline $\operatorname{Mn} 257.610$ & 1 & Y 488.368 & 0 \\
\hline Mo 201.512 & 88 & Zn 213.857 & 988 \\
\hline Zr 328.470 & 1 & & \\
\hline
\end{tabular}

Pada Tabel 3. terlihat bahwa kandungan sulfur pada minyak pelumas bekas SAE 15W-40 CI-4 cukup tinggi yaitu sebesar 1136440.

\section{Pengujian Sampel Pelumas}

Tabel 4. Data hasil pengujian sampel VI, Titik Tuang, Titik Nyala

\begin{tabular}{cccccccc}
\hline & & \multicolumn{2}{c}{ Viskositas Indeks } & \multicolumn{2}{c}{ Titik Tuang $\left({ }^{\circ} \mathrm{C}\right)$} & \multicolumn{2}{c}{ Titik Nyala $\left({ }^{\circ} \mathrm{C}\right)$} \\
\cline { 3 - 7 } No. & Jenis Pelumas & $\begin{array}{c}\text { Pelumas } \\
\text { Mineral }\end{array}$ & $\begin{array}{c}\text { Pelumas } \\
\text { Sintetis }\end{array}$ & $\begin{array}{c}\text { Pelumas } \\
\text { Mineral }\end{array}$ & $\begin{array}{c}\text { Pelumas } \\
\text { Sintetis }\end{array}$ & $\begin{array}{c}\text { Pelumas } \\
\text { Mineral }\end{array}$ & $\begin{array}{c}\text { Pelumas } \\
\text { Sintesis }\end{array}$ \\
\hline 1 & $\begin{array}{c}\text { DEO SAE 15W-40 } \\
\text { API CI-4 }\end{array}$ & 144 & 165 & -30 & -30 & 212 & 222 \\
2 & $\begin{array}{c}\text { PCMO API SN } \\
\text { SAE 10W-40 }\end{array}$ & 146 & 168 & -30 & -30 & 216 & 222 \\
3 & $\begin{array}{c}\text { MCO API SL } \\
\text { SAE 10W-30 }\end{array}$ & 150 & 167 & -36 & -36 & 216 & 222 \\
4 & $\begin{array}{c}\text { HO ISO VG 32 } \\
\text { TO API TO-4 SAE }\end{array}$ & 110 & 140 & -9 & -9 & 228 & 240 \\
5 & $\begin{array}{c}\text { TOW } \\
\text { 10W }\end{array}$ & 107 & 138 & --30 & -30 & 224 & 236 \\
\hline
\end{tabular}




\section{Viskositas Indeks}

Viskositas indeks adalah Angka yang menunjukkan kualitas dari ketahanan viskositas pelumas terhadap perubahan suhu. Semakin besar angka viskositas indeks maka semakin bagus kualitas pelumas tersebut. Dengan kata lain, Pelumas yang memiliki viskositas indeks yang tinggi adalah pelumas yang viskositasnya tidak mudah berubah karena adanya perubahan suhu Terbukti pada penelitian ini, nilai viskositas indeks pada beberapa macam pelumas sintesis lebih tinggi nilainya dibandingkan dengan pelumas mineralnya. Karena minyak pelumas dasar sintesis lebih stabil viskositasnya terhadap perubahan suhu yang membuat produk pelumas yang dibuat dari minyak pelumas dasar sintesis ini akan meningkat viskositas indeksnya dibandingkan dengan pelumas mineral. Pelumas yang baik adalah pelumas yang memiliki nilai viskositas indeks yang tinggi karena pelumasannya akan berlangsung lebih baik pada rentang perbedaan suhu yang lebih lebar. Dengan begitu fungsi pelumas tersebut sebagai media untuk mengurangi keausan akan berjalan dengan baik.

\section{Titik Tuang (Pour Point)}

Titik tuang merupakan suhu terendah dimana suatu cairan mulai tidak bisa mengalir dan kemudian menjadi beku. Titik tuang perlu diketahui untuk minyak pelumas yang dalam pemakaiannya mencapai suhu yang dingin atau bekerja pada lingkungan udara yang dingin. Apabila pelumas tersebut membeku saat digunakan, maka akan berdampak fatal pada komponen mesin ataupun benda bergerak lainnya karena fungsi dari pelumas tersebut tidak akan bekerja sama sekali. Pelumas sintesis lebih tahan terhadap suhu rendah dibandingkan pelumas mineral. Pelumas sintesis bisa tahan sampai suhu $-36{ }^{\circ} \mathrm{C}$ tentu saja harus dikolaborasikan dengan Additive Pour Point Depressant untuk bisa mendapatkan titik tuang yang sangat rendah. Pengaruh Minyak pelumas dasar terhadap ketahanan wujud pelumas terhadap suhu rendah agar tidak membeku memang tidak terlalu signifikan. Karena memang sebagian besar dari minyak pelumas dasar sendiri akan membeku pada suhu $-15{ }^{\circ} \mathrm{C}$. Kinerjanya dibantu oleh Additive Pour Point Depressant untuk bisa mencapai suhu $<-15{ }^{\circ} \mathrm{C}$.

\section{Titik Nyala (Flash Point)}

Titik nyala merupakan suatu keadaan uap jenuh yang dihasilkan dari laju penguapan terendah di atas permukaan minyak pelumas pada suhu tertentu dimana pada keadaan ini minyak lumas telah mampu terbakar sesaat (menyala) ketika bertemu dengan sumber panas yang berada dalam lingkungan pelumas tersebut. Pengukuran titik nyala sangat penting mengingat pelumas bekerja pada kondisi suhu yang panas seperti pada pelumas mesin. Titik nyala tersebut menandakan sampai sejauh mana pelumas tersebut dapat bekerja pada suhu yang tinggi. Pelumas yang baik adalah pelumas yang memiliki nilai titik nyala yang tinggi.

\section{Pengaruh Penambahan Karbon Aktif, Bentonit dan Pasir Silika Sebagai Penyerap}

Pengaruh penambahan karbon aktif, bentonit dan pasir silika pada pelumas bekas SAE 15W-40 API CI-4 mempengaruhi sifat fisik yang dapat dilihat pada Tabel 5. 
Tabel 5. Penambahan Bentonit dan Pasir Silika

\begin{tabular}{cccc}
\hline Jenis Thickener & Viskositas Kinematik $(\mathrm{cSt})$ & $\mathrm{IV}$ & $\mathrm{Sg}$ \\
\hline Karbon aktif & 77,866 & 0,009 & 0,885 \\
Pasir Silika & 72,378 & 0,010 & 0,881 \\
Bentonit & 79,465 & 0,010 & 0,884 \\
\hline
\end{tabular}

Penjerapan dimaksudkan untuk menghilangkan kontaminan atau kotoran yang terdapat di dalam minyak pelumas bekas hingga diperoleh minyak pelumas yang lebih baik (jernih). Hasil analisa terhadap parameter uji viskositas kinematik, indeks viskositas (IV), dan spesifik gravity (Sg), semakin jernih minyak pelumas hasil percobaan berarti semakin banyak kontaminan yang terjerab dan semakin sedikit kontaminan yang ada di minyak pelumas sehingga membuat nilai specific gravity (SG) semakin kecil dan nilai viskositas kinematik juga semakin kecil, terlihat pada Tabel 5. bahwa pasir silika merupakan sebagai media penjernih pada pengolahan minyak pelumas bekas SAE 15W-40 API CI-4.

\section{KESIMPULAN}

Berdasarkan hasil penelitian dan pengujian kualitas minyak pelumas sintesis, mineral dan pelumas bekas dapat disimpulkan bahwa:

- Penggunaan minyak lumas dasar sintesis membuat kualitas pelumas menjadi lebih baik khususnya dari segi viskositas indeks, titik tuang dan titik nyala.

- Semakin bagus atau semakin tinggi golongan bahan baku yang digunakan dalam pembuatan pelumas maka semakin baik kualitasnya serta semakin lama waktu pemakaian dari pelumas tersebut.

- Pasir Silika memiliki penjerap yang cukup baik dibandingkan dengan penjerap karbon aktif dan bentonite.

\section{UCAPAN TERIMAKASIH}

Ucapan terimakasih kami sampaikan kepada Fakultas Teknologi Industri Universitas Jayabaya yang telah memberikan hibah penelitian tahun akademik 2018/2019, dengan nomor kontrak 71.210/DEK/FTI-UJ/XII/2018.

\section{DAFTAR NOTASI}

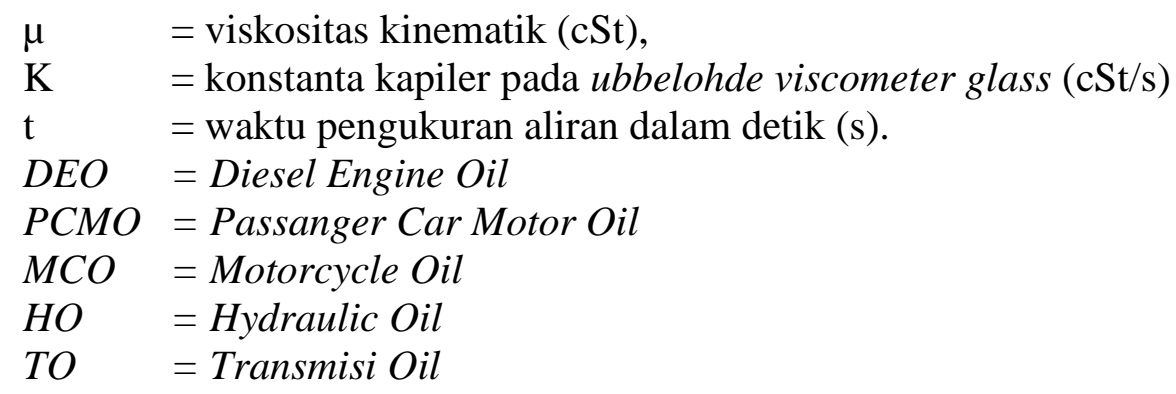




\section{DAFTAR PUSTAKA}

[1] A. Ruggiero, R. D’Amato, M. Merola, P. Valášek and M. Müller, "On the Tribological Performance of Vegetal Lubricants: Experimental Investigation on Jatropha Curcas L. oil," Procedia Engineering, vol. 149, pp. 431-437, 2016.

[2] H. Ong, A. Silitonga, H. Masjuki, T. M. I. Mahlia, W. T. Chong and M. Boosroh, "Production and comparative fuel properties of biodiesel from non-edible oils: Jatropha curcas, Sterculia foetida and Ceiba pentandra," Energy Conversion and Management, vol. 73, p. 245-255, 2013.

[3] T. M. Panchal, A. Patel, D. Chauhan, M. Thomas and J. V. Patel, "A methodological review on bio-lubricants from vegetable oil based resources," Renewable and Sustainable Energy Reviews, vol. 70, pp. 65-70, 2017.

[4] J. Ssempebwa and D. O. Carpenter, "The generation, use and disposal of waste crankcase oil in developing countries: A case for Kampala district, Uganda," Journal of Hazardous Materials, vol. 161, no. 2-3, pp. 835-841, 2008.

[5] A. L. Miller, C. B. Stipe, M. C. Habjan and G. G. Ahlstrand, "Role of Lubrication Oil in Particulate Emissions from a Hydrogen-Powered Internal Combustion Engine," Environmental Science and Technology, vol. 41, no. 19, pp. 6828-6835, 2007.

[6] I. Monika and D. F. Umar, "Pemanfaatan Bentonit Sebagai Penjernih Minyak Pelumas Bekas Hasil Proses Daur Ulang Dengan Batubara," Jurnal Bahan Galian, vol. 12, no. 33, pp. 17-21, 2008.

[7] N. S. Nigrum, "Optimasi Proses Daur Ulang Minyak Pelumas Bekas Menggunakan Batubara Peringkat Rendah sebagai Penyerap Kontaminan," Pusat Penelitian dan Pengembangan Teknologi Mineral dan Batubara, Kementerian ESDM, 2010.

[8] M. H. Prawira, "Penurunan Kadar Minyak pada Limbah Bengkel dengan Menggunakan Reaktor Pemisah Minyak dan Karbon Aktif serta Zeolit sebagai Media Adsorben," Universitas Islam Indonesia, Yogyakarta, 2008.

[9] Sugondo, A. Latif and N. Samosir, "Karakterisasi Distribusi Zeolit Dalam Pelet Mentah UO2 Dengan WDX- SEM," PEBN-BATAN, Jakarta, 1998.

[10] J. Setiaka, I. Ulfin and N. Widiastuti, "Adsorpsi Ion Logan CU (II) Dalam Larutan Pada Abu Dasar Batubara Menggunakan Metode Kolom," KIMIA FMIPA, ITS, 2010. 